\title{
Indirect calorimetry can be used to measure cardiac output in septic patients? ${ }^{1}$
}

\author{
A calorimetria indireta pode ser utilizada para medir o débito cardíaco em pacientes \\ sépticos?
}

\author{
Maria Auxiliadora Martins ${ }^{\mathrm{I}}$, Francisco Antônio Coletto ${ }^{\mathrm{II}}$,Antônio Dorival Campos ${ }^{\mathrm{III}}$, Anibal Basile-Filho ${ }^{\mathrm{IV}}$ \\ ${ }^{I} \mathrm{MD}$, PhD and Surgeon-in-Chief, Division of Intensive Care Unit, Department of Surgery and Anatomy, Ribeirão Preto Faculty of \\ Medicine, University of São Paulo, Brasil

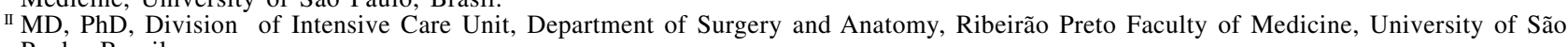 \\ Paulo, Brazil. \\ ${ }^{\text {III }} \mathrm{MD}$, PhD, Department of Social Medicine, Ribeirão Preto Faculty of Medicine, University of São Paulo, Brazil. \\ Iv Associate Professor, Division of Intensive Care Unit, Department of Surgery and Anatomy, Ribeirão Preto Faculty of Medicine, \\ University of São Paulo, Brazil.
}

\begin{abstract}
Purpose: The aim of this study was to compare two different cardiac output (CO) monitoring systems based on the thermodilution principle (Thermo-CO) and indirect calorimetry (Fick mixed-CO) in septic patients. Methods: Prospective study in septic patients admitted in an intensive care unit of a university hospital. Nineteen patients aged on average 45.4 \pm 21.5 years were enrolled in the study. Four series of hourly measurements by the two techniques were carried out simultaneously. Results: No significant differences were observed between Thermo-CO and Fick mixed-CO (7.0 \pm 1.8 L.min ${ }^{-1}$ and 6.4 \pm 1.7 L.min ${ }^{-1}$ ). Parallel analysis of Fick mixed-CO and Fick atrial-CO was performed introducing a correction factor for the eight atrial samples in order to adjust the values of oxygen saturation obtained from atrial blood (Fick corrected atrial-CO) to those obtained from mixed venous blood. No significant differences could be detected between Fick mixed-CO and Fick corrected atrial-CO. The correlation coefficients of Thermo CO/Fick mixed-CO and Fick mixed-CO/ Fick corrected atrial-CO were 0.84 and 0.94, respectively. Conclusion: We observed that the agreement between the two methods was satisfactory on the basis of the decisions made for treatment. Indirect calorimetry is useful to measure CO in patients with septic shock.
\end{abstract}

Key words: Indirect Calorimetry. Cardiac Output. Septic Shock. Intensive Care Setting.

\section{RESUMO}

Objetivo: O objetivo deste estudo foi comparar as medidas do débito cardíaco (DC) obtidas pela termodiluição (DC-termo) e pela calorimetria indireta (DC-Fick misto) em pacientes com choque séptico. Métodos: Estudo prospectivo em pacientes sépticos internados em unidade de terapia intensiva de um hospital universitário. Foram estudados 19 pacientes $(45,4 \pm$ 21,5 anos). Foram realizadas quatro séries de medidas do DC pelos dois métodos, simultaneamente. Resultados: Não houve diferenças significativas entre os valores do DC-termo e DC-Fick misto (7,0 \pm 1,8 L.min ${ }^{-1}$ e 6,4 $\pm 1,7$ L.min ${ }^{-1}$, respectivamente). Na avaliação dos oito casos (DC-Fick misto/DC Fick atrial), introduziu-se um fator de correção para aproximar os valores do conteúdo de $\mathrm{O}_{2}$ atrial (DC-Fick atrial corrigido) com o venoso misto. Não houve diferença significativa do DC-Fick misto e DC-Fick atrial corrigido nos 4 tempos. A correlação foi de 0.84 para o DC-termo/DC-Fick misto e de 0.94 para o DC-Fick misto/DC-Fick atrial corrigido. Conclusão: A calorimetria indireta é um bom método para a medida do DC em pacientes vítimas de choque séptico, sobretudo nos casos onde a monitorização hemodinâmica invasiva não está disponível ou está contra indicada.

Descritores: Calorimetria Indireta. Débito Cardíaco. Choque Séptico. Unidade de Terapia Intensiva. 


\section{Introduction}

The cardiovascular system is a frequent target of sepsis and therefore cardiovascular changes interfere with the prognosis. Normalization of cardiac output $(\mathrm{CO})$ during the first 48 hours is correlated with survival. ${ }^{1}$ Sepsis, trauma and major surgery increase metabolism and therefore $\mathrm{CO}$. Septic shock causes a hyperdynamic state characterized by tachycardia, increased $\mathrm{CO}$, and reduced systemic vascular resistance. ${ }^{2}$ Since the function of the heart is to provide an adequate supply of oxygen and nutrients to all tissues of the organism, $\mathrm{CO}$ monitoring becomes essential in clinical situations involving hemodynamic instability. None of the methods currently used provides definitive parameters for the monitoring of an adequate oxygen supply to tissues. $\mathrm{CO}$ is one of the most important variables in the context of tissue perfusion. In addition, it participates in the calculations of other hemodynamic and oxygenation variables such as systemic vascular resistance (SVR), pulmonary vascular resistance (PVR), and oxygen supply $\left(\mathrm{DO}_{2}\right)$. Fick's method was initially limited mainly in terms of the determination of oxygen consumption. The margin of error for $\mathrm{CO}$ calculation by Fick's method is about $10 \% .^{3}$ An imprecise oxygen consumption value can increase $\mathrm{CO}$ variability by more than $10 \%$, especially when the presumed consumption and not the directly measured consumption is used. ${ }^{4}$

The objectives of the present study were to compare $\mathrm{CO}$ measurement by thermodilution (Thermo$\mathrm{CO}$ ) and by indirect calorimetry (Fick's method, Fick mixed-CO) in patients victims of septic shock and to use atrial venous blood instead of mixed venous blood for $\mathrm{CO}$ calculation, with the addition of a correction factor in an attempt to obtain an atrial $\mathrm{O}_{2}$ content value close to that of mixed content.

\section{Methods}

A prospective clinical study was conducted in the Intensive Care Unit of the University Hospital, Faculty of Medicine of Ribeirão Preto, University of São Paulo. The study was approved by the Research Ethics Committee of the University Hospital, Faculty of Medicine of Ribeirão Preto, and free informed consent was obtained in all cases. The study involved adult patients of both sexes with septic shock submitted to volume restoration and hemodynamic stabilization. The criteria for the diagnosis of septic shock were those established by the consensus conference held by the American College of Chest Physicians/Society of Critical Care Medicine. ${ }^{5}$ The inclusion criterion was the presence of septic shock from the first to the fifth day of evolution, with an indication of invasive hemodynamic monitoring. Exclusion criteria were: age $>85$ and $<15$ years, need for oxygen fraction in inspired air $\left(\mathrm{FiO}_{2}\right)>0.6$, mean arterial pressure $<50 \mathrm{mmHg}$, and hourly diuresis $<50 \mathrm{~mL} \cdot \mathrm{h}^{-1}$.
Upon admission to the Intensive Care Unit, all patients were stratified according to the APACHE II severity index ${ }^{6}$ and to the system of sepsis grading. ${ }^{7}$ All patients were submitted to invasive and noninvasive hemodynamic monitoring, blood volume restoration, mechanical ventilation (Servo 900C, Siemens, Sweden), treatment with antibiotic and vasoactive drugs, and nutritional support according to real energy expenditure calculated by indirect calorimetry. The patients were sedated with benzodiazepines and/or opiates and a neuromuscular blocker was used when necessary. The current weight of the patients was obtained with a portable electrinic scale (Slingscale 2002, Hill-Rom, Hillenbrand Industries, USA). The protocol lasted, on average, eight hours and included four series of $\mathrm{CO}$ measurements by thermodilution and by indirect calorimetrty. All patients were submitted to invasive hemodynamic monitoring with a Swan-Ganz 7 F caliber catheter with an 8.5 F introducer (Baxter Healthcare Corp, USA) by puncture of the internal jugular or subclavian vein. $\mathrm{CO}$ measurement by thermodilution was performed with a monitor (Dixtal 2010, Biomédica, Brazil). A chest X-ray was obtained after the procedure to assess the position of the catheter and to exclude possible complications. $\mathrm{CO}$ was determined by thermodilution by injection of $10 \mathrm{~mL} 0.9 \%$ saline solution at a temperature of 0 to $5^{\circ} \mathrm{C}$ over a period of two to four seconds into the proximal orifice of the catheter (right atrium), with the patient in horizontal dorsal decubitus. Three measurements were made always at the end of expiration and the mean of their values was considered to be the definitive value, with a difference of a maximum of $10 \%$ being accepted between them. Venous blood samples were collected in parallel from the proximal orifice (right atrium) and distal orifice (pulmonary artery) of the SwanGanz catheter, and arterial blood was obtained from the radial artery for blood gas analysis, which permitted us to assess hemoglobin concentration, oxygen saturation in arterial $\left(\mathrm{SaO}_{2}\right)$ and venous $\left(\mathrm{SvO}_{2}\right)$ blood and partial oxygen pressure in arterial $\left(\mathrm{PaO}_{2}\right)$ and venous $\left(\mathrm{PvO}_{2}\right)$ blood.

After calculation of oxygen consumption by indirect calorimetry and of oxygen content in arterial and venous blood, it was possible to calculate $\mathrm{CO}$ by the Fick equation as follows:

$$
\mathrm{CO}=\mathrm{VO}_{2} /\left(\mathrm{CaO}_{2}-\mathrm{CvO}_{2}\right) \times 10\left(\mathrm{~L} \cdot \mathrm{min}^{-1}\right)
$$

The equation below shows the calculation of $\mathrm{CO}$ using a correction factor (Fick corrected atrial $\mathrm{CO}$ ):

$$
\mathrm{CO}=\mathrm{VO}_{2} /\left(\mathrm{CaO}_{2}-\mathrm{CvO}_{2} \times \mathrm{F}\right) \times 10\left(\mathrm{~L} \cdot \mathrm{min}^{-1}\right)
$$

\section{Where:}

$\mathrm{VO}_{2}=\mathrm{O}_{2}$ consumption.

$\mathrm{CaO}_{2}=$ Arterial $\mathrm{O}_{2}$ content.

$\mathrm{CvO}_{2}=$ Venous $\mathrm{O}_{2}$ content extracted from the right atrium (proximal orifice of the catheter).

$\mathrm{F}=$ Correction factor (0.9222). 
F was obtained from the calculation of the mean (in $\%$ ) of the differences between mixed venous oxygen content and atrial oxygen content subtracted from $100 \%$. The correction factor found was 0.9222 .

Indirect calorimetry was applied to all patients using a portable DELTATRAC II Metabolic Monitor (DatexOhmeda, Finland), with barometric and gas pressure being calibrated before each protocol. Four series of 30 consecutive measurements of minute by minute $\mathrm{O}_{2}$ consumption $\left(\mathrm{VO}_{2}\right)$ were made, and the mean $\mathrm{VO}_{2}$ of each series was used to calculate CO.

The two methods for evaluation were compared by the nonparametric Wilcoxon sign test for two correlated samples. The approximate nonparametric Friedman test for large samples was also used. When statistically significant differences were detected, the nonparametric multiple comparisons test was used, based on the Friedman rank sum test. The level of significance was set at $\mathrm{p}<0.05$ for all comparisons. The Pearson correlation coefficient was also calculated for the $\mathrm{CO}$ variable obtained with the two methods. $^{8}$

\section{Results}

We evaluated 19 hemodynamically stable patients (14 males and five females) with a diagnosis of septic shock admitted to the Intensive Care Unit between the third and fifth day of evolution. Mean age was 45.4土 21.5 years. The mean APACHE II prognostic index was 22.4 \pm 6.8 , with a calculated death risk of $46.1 \pm 26.8 \%$. The mean sepsis score was $21.1 \pm 8.6$. The main clinical and demographic data for the patients are listed in Table 1. Most patients $(84.21 \% ; \mathrm{n}=16)$ were victims of pneumonia, with acute respiratory insufficiency. The other three patients had severe cellulitis in the lower right limb, an intraabdominal abscess and peritonitis, respectively. Eight of the 19 patients studied (42.1\%) died.

TABLE 1 - Clinical diagnoses and demographic data of the population studied. AP II = APACHE II prognostic index; Death risk = death risk calculated by the AP II (\%); SS = Sepsis Score (grading of sepsis).

\begin{tabular}{|c|c|c|c|c|c|c|c|c|}
\hline $\begin{array}{r}\text { Infectious } \\
\text { diagnosis }\end{array}$ & Sex & Age (years) & $\begin{array}{c}\text { Weight } \\
\text { (kg) }\end{array}$ & $\begin{array}{l}\text { Height } \\
(\mathrm{cm})\end{array}$ & AP II & Death risk & SS & Death \\
\hline Pneumonia & $\mathrm{M}$ & 28 & 67 & 173 & 20 & 28 & 27 & no \\
\hline Pneumonia & $\mathrm{F}$ & 39 & 53 & 150 & 31 & 73 & 21 & yes \\
\hline Pneumonia & M & 35 & 74 & 177 & 12 & 11 & 26 & no \\
\hline Pneumonia & $\mathrm{F}$ & 38 & 62 & 162 & 11 & 14 & 12 & no \\
\hline Pneumonia & M & 19 & 67 & 177 & 17 & 11 & 45 & no \\
\hline Pneumonia & M & 16 & 65 & 174 & 26 & 55 & 09 & no \\
\hline Pneumonia & $\mathrm{F}$ & 78 & 70 & 163 & 28 & 66 & 10 & no \\
\hline Pneumonia & M & 32 & 63 & 167 & 28 & 72 & 11 & no \\
\hline Pneumonia & M & 31 & 70 & 176 & 15 & 16 & 17 & no \\
\hline Pneumonia & M & 72 & 62 & 160 & 28 & 78 & 28 & yes \\
\hline Pneumonia & M & 67 & 77 & 170 & 16 & 24 & 19 & yes \\
\hline Pneumonia & $\mathbf{M}$ & 83 & 50 & 160 & 27 & 60 & 22 & no \\
\hline Cellulitis & M & 22 & 70 & 170 & 26 & 73 & 25 & no \\
\hline Pneumonia & M & 69 & 60 & 160 & 33 & 88 & 26 & yes \\
\hline Pneumonia & M & 48 & 80 & 177 & 24 & 52 & 15 & no \\
\hline Pneumonia & $\mathrm{M}$ & 68 & 58 & 160 & 27 & 63 & 16 & no \\
\hline Pneumonia & M & 55 & 80 & 170 & 27 & 58 & 17 & yes \\
\hline Abdominal abscess & $\mathrm{F}$ & 41 & 88 & 162 & 14 & 11 & 28 & no \\
\hline Peritonitis & $\mathrm{F}$ & 23 & 62 & 160 & 16 & 23 & 27 & yes \\
\hline Median & & 39.0 & 67.0 & 167.0 & 26.0 & 55.0 & 21.0 & \\
\hline Mean & & 45.4 & 66.2 & 166.7 & 22.4 & 46.1 & 21.1 & \\
\hline SD & & \pm 21.5 & \pm 9.6 & \pm 7.7 & \pm 6.8 & \pm 26.8 & \pm 8.6 & \\
\hline
\end{tabular}


The mean CO calculated from the 76 values corresponding to the 19 patients under study, obtained by the thermodilution method (Thermo-CO) was 7.0 \pm 1.8 L.min ${ }^{1}$, and the value obtained by the Fick method (Fick mixedCO) was $6.4 \pm 1.7 \mathrm{~L} . \mathrm{min}^{-1}$. There was no significant difference in $\mathrm{CO}$ obtained by the two methods at $\mathrm{T} 1, \mathrm{~T} 2$ and $\mathrm{T} 3$. However, there was a significant difference at $\mathrm{T} 4(\mathrm{p}<0.05)$. The mean value of the differences of the $\mathrm{CO}$ values in the four series of measurements was - $0.64 \pm 0.24 \mathrm{~L} \cdot \mathrm{min}^{-1}(9.1 \pm$ $3.3 \%)$. The correlation coefficient between mean Thermo$\mathrm{CO}$ and Fick mixed-CO values was 0.84 (Figure 1).

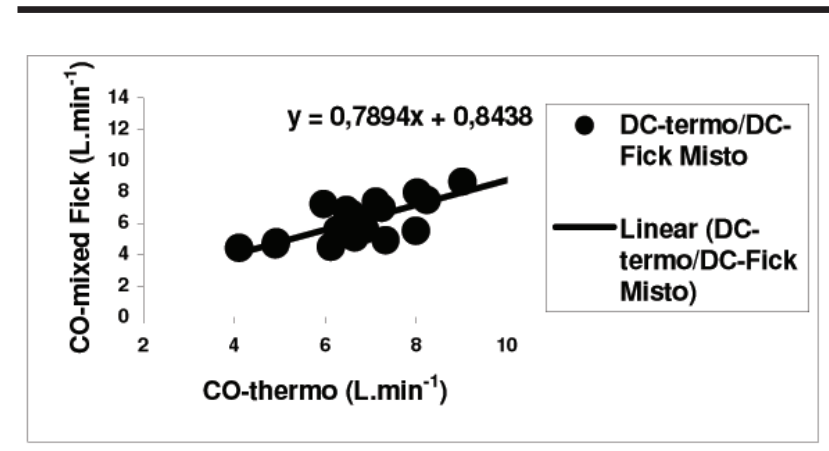

FIGURE 1 - Correlation coefficient between the mean $\mathrm{CO}$ values obtained by thermodilution and by Fick's mixed method $(n=19 ; r=0.84)$.

Fick mixed-CO and Fick corrected atrial-CO were compared in eight patients in order to assess the use of atrial venous blood as a source for the calculation of venous oxygen content. Mean Fick mixed-CO was $6.0 \pm 1.2$ L.min ${ }^{-1}$ and mean Fick corrected atrial-CO was $8.2 \pm 2.4$ L.min ${ }^{-1}$. There was a significant difference in mean $\mathrm{CO}$ measured by Fick mixed-CO and Fick corrected atrial-CO at all four time points. The correlation coefficient detected between Fick mixed-CO and Fick corrected atrial-CO was 0.93 (Figure 2).

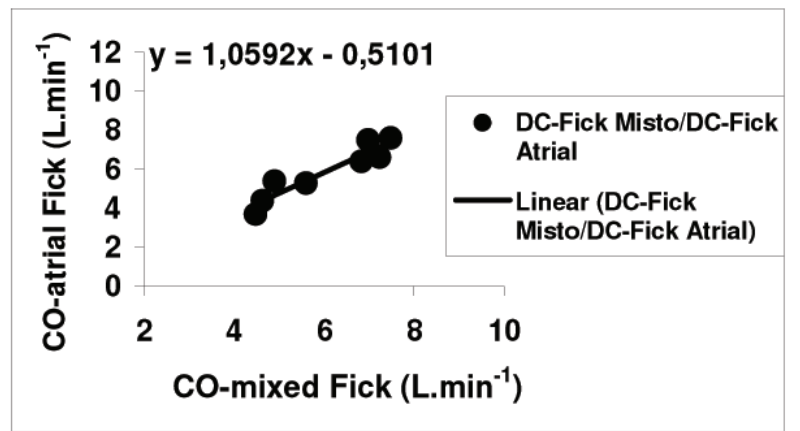

FIGURE 2 - Correlation coefficient between the mean CO values obtained by Fick's mixed method and Fick's atrial method $(n=8 ; r=0.93)$.
Significant differences were detected between mean mixed venous $\mathrm{O}_{2}$ content and atrial $\mathrm{O}_{2}$ content. After atrial $\mathrm{O}_{2}$ content was corrected using the correction factor, the mean content values were much closer, with a correlation of 0.94 . The mean of mean Fick mixed-CO values was $6.0 \pm 1.2$ L. min $^{-1}$ and the mean of Fick corrected atrial-CO was 5.9 \pm 1.4 L.min ${ }^{-1}$.

There was no significant difference between Fick mixed-CO and Fick corrected atrial-CO at times T1-T4. The mean of the difference of $\mathrm{CO}$ values in the four series of measurements was $0.14 \pm 0.18 \mathrm{~L} \cdot \mathrm{min}^{-1}(3.3 \pm 1.3 \%)$. After CO was calculated by corrected atrial blood we found a correlation of 0.94 (Figure 3).

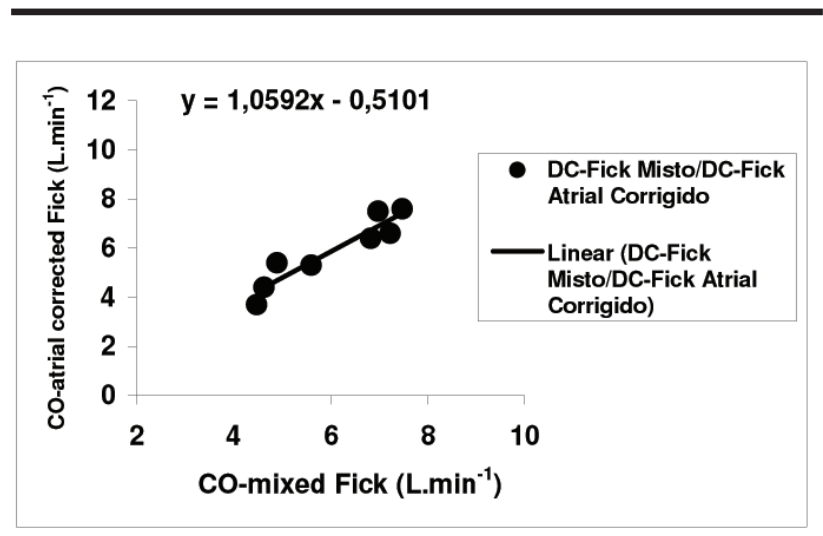

FIGURE 3 - Correlation coefficient between the mean $\mathrm{CO}$ values obtained by Fick's mixed method and corrected Fick's atrial method $(\mathrm{n}=8 ; \mathrm{r}=0.94)$.

When mean $\mathrm{CO}$ values were compared by the Thermo-CO and Fick corrected atrial-CO methods in the group of eight patients, there was a significant difference at $\mathrm{T} 1$ and T3 $(\mathrm{p}<0.05)$, but no difference at T2 and T4. This difference may probably be related to the smaller number of patients in this group $(n=8)$. On the basis of the results obtained, there was no significant difference between Thermo-CO and Fick mixed-CO at times T1, T2 and T3, but a difference was observed only at $\mathrm{T} 4$. The correlation coefficient between Thermo-CO and Fick mixed-CO was $\mathrm{r}=0.84(\mathrm{n}=19)$. There was a significant difference between the Fick mixed-CO and Fick atrial-CO measurements at all four time points (T1 to T4) even though the correlation coefficient was $r=0.93(n=8)$. After the correction factor was applied, the correlation between atrial and mixed $\mathrm{O}_{2}$ content was $\mathrm{r}=0.94$. There was no significant difference between Fick mixed-CO and Fick corrected atrial-CO at the four time points (T1 to T4) and the correlation coefficient was $0.94(n=8)$. When we compared Fick corrected atrial-CO with thermodilution in the eight cases we observed a significant difference at $\mathrm{T} 1$ and $\mathrm{T} 3$ and no difference at T2 and T4. As commented earlier, this difference could be explained by the smaller number of patients studied $(n=8)$. The mean $\mathrm{CO}$ values obtained by thermodilution and by calorimetry using mixed blood, atrial blood and corrected atrial blood are illustrated in Figure 4, which shows a sharp discrepancy between mean Fick 
corrected atrial-CO values and all other values. The mean difference in mean $\mathrm{CO}$ value sobtained in the present study by the two methods (Thermo-CO and Fick mixed$\mathrm{CO}$ ) was $0.4 \pm 0.9 \mathrm{~L} \cdot \mathrm{min}^{-1}$ for $\mathrm{CO}$ values lower than $7 \mathrm{~L} \cdot \mathrm{min}^{-}$ ${ }^{1}$ and $0.9 \pm 1.1 \mathrm{~L}^{-\mathrm{min}^{-1}}$ for mean $\mathrm{CO}$ values higher than 7 L. $\min ^{-1}$.

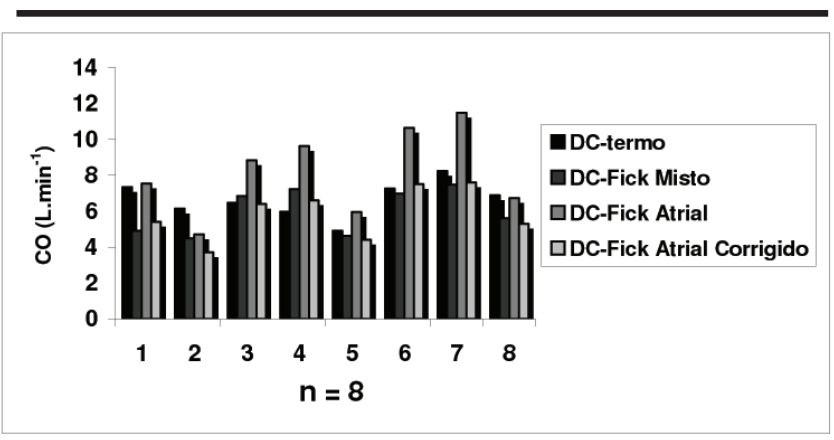

FIGURE 4 - $\quad$ Mean $\mathrm{CO}$ values obtained by thermodilution and by calorimetry using mixed venous blood, atrial blood and corrected atrial blood $(n=8)$. CO values were always higher when atrial blood was used, with closer values when blood was corrected with the correction factor.

\section{Discussion}

$\mathrm{CO}$ is an essential hemodynamic parameter for the clinical management of patients with imbalance between oxygen supply and oxygen requirement. If $\mathrm{CO}$ can be determined during an early stage of the illness and in a less invasive manner, it is possible to intervene positively in the clinical course of patients victims of septic shock, while at the same time avoiding the complications inherent to the passage of a Swan-Ganz catheter. Thermodilution has limitations inherent to its invasive nature and also concerning accuracy in situations such as the presence of an intracardiac shunt and pulmonary and/or tricuspid valve disease. In a shunt from the right to the left, part of the fluid passes through the communication, with the registration of an abbreviated thermodilution curve similar to the high output curve. In the shunt from the left to the right the curve is also abbreviated because the blood coming from the left heart increases the volume in the right chambers, diluting the injected solution. Thus, in shunt situations false high $\mathrm{CO}$ measurements are obtained. ${ }^{9}$ In tricuspid regurgitation there is reflux of the indicator solution through the valve towards the right atrium. This produces a prolonged low-amplitude thermodilution curve, casing false low CO measurements ${ }^{10}$. In mechanically ventilated patients with positive pressure there is an increase in pressure in the right chambers favoring the occurrence of tricuspid regurgitation and therefore an error in $\mathrm{CO}$ measurement by thermodilution. ${ }^{10}$ In low output situations, the CO curve are of low amplitude, affecting the precision of thermodilution by reducing the signal/ interference ratio. According to van Grondelle et al. ${ }^{11}$ in situations of low output there is an overestimate of CO.

Less invasiveness and more accurate information are a priority in the treatment of critically ill patients. In principle, the Fick method proposed here requires the use of a central venous catheter for blood collection. However, central catheterization is indicated for most intensive care patients for other reasons. Thus, it is a less invasive technique than thermodilution. The advantage of the Fick method resides in the greater accuracy of $\mathrm{CO}$ calculation in situations of low systemic flows and is preferable to thermodilution in these cases ${ }^{11}$. It is also independent of factors that affect the shape of the curve, which lead to erroneous $\mathrm{CO}$ values when thermodilution is used. Finally, this technique is also a less invasive method. Less invasive techniques are not widely used for several reasons such as high cost, complexity and margin of error. In addition, $\mathrm{CO}$ measurement is not a parameter that can be assessed separately. In contrast, the Swan-Ganz catheter provides other hemodynamic data such as capillary pulmonary pressure and cardiac work. However, using the SwanGanz catheter, $\mathrm{CO}$ is measured by the thermodilution technique, which has the limitations mentioned earlier. The Fick method, in addition to providing the $\mathrm{CO}$ value, permits the measurement of other hemodynamic variables such as SVR, PVR, $\mathrm{DO}_{2}$ in earlier stages of clinical evolution, since it does not involve greater invasiveness. Some criticisms have been moved against the Fick technique, such as difficulty in collecting expired gases using the Douglas bag classically employed for this purpose and the need to collect mixed arterial and venous blood.

With recent technological advances, more accurate equipment for the measurement of oxygen consumption, such as a calorimeter, has become available. This has attracted interest in the use of the Fick method for CO determination in critically ill patients. However, it should be kept in mind that the use of a calorimeter requires trained personnel. Nevertheless, the technique is easy to execute and provides not only oxygen consumption but also $\mathrm{CO}_{2}$ production, respiratory coefficient, real energy expenditure, and other important variables for the management of critically ill patients, which are calculated by mathematical equations. An important variable is oxygen supply, which can be calculated from $\mathrm{CO}$ and arterial oxygen content obtained by collecting an arterial blood sample. 
Indirect calorimetry is a noninvasive and practically risk-free method that provides body oxygen consumption in a more precise manner since the variable is measured directly and not by calculations, as done when data of invasive hemodynamic monitoring are used. Thus, the pulmonary oxygen consumption is considered. There is a limitation of the use of this technique in patients who use high inspired $\mathrm{O}_{2}$ fractions. However, some studies have reported the use of $\mathrm{VCO}_{2}$ as a source for the calculation of $\mathrm{CO}$, since this variable is not under the influence of high $\mathrm{FiO}_{2}$ rates. ${ }^{12,15}$ This method can also be used in early situations of hemodynamic instability, in which usually there is no need for high $\mathrm{FiO}_{2}$, serving as a screening for the indication of invasive hemodynamic monitoring.

The value of the measurement of $\mathrm{O}_{2}$ saturation in right atrium or superior vena cava blood has been questioned, especially when saturation is higher than $65 \% .{ }^{16} \mathrm{O}_{2}$ saturation in atrial blood and in the superior vena cava differs from that in mixed blood. This is due to the fact that oxygen consumption varies in the different organs, with greater oxygen consumption in the brain and lower oxygen consumption in the kidneys out of proportion with its flow in blood, causing $\mathrm{O}_{2}$ saturation to be lower in the superior vena cava than in the inferior vena cava. ${ }^{17,18}$ Nevertheless, these regional saturation data are valid for normal conditions. Reduced brain metabolism occurs is critically ill sedated patients, with a consequent reduction in cerebral oxygen consumption. In addition, the hypermetabolic state of patients with septic shock can alter $\mathrm{O}_{2}$ saturation in the various vascular beds.

A good correlation between atrial and mixed venous saturation has been described by some authors. ${ }^{19,20}$ Reinhart et al. ${ }^{21}$ compared mixed venous saturation to saturation in the superior vena cava in an experimental model and demonstrated an excellent correlation $(r=0.97)$. Lee et al. ${ }^{22}$ studied 29 stable patients and 15 patients in circulatory shock (septic, hemorrhagic and neurogenic) and detected a good correlation between venous atrial and mixed saturation. In the present study, the use of atrial blood for calculation of venous oxygen content showed a good correlation with venous content, especially when we used a correction factor $(r=0.94)$. Also, the use of this factor improved the method since it caused the $\mathrm{CO}$ values to be closer to those obtained with mixed venous blood and with thermodilution. Despite the good correlation between Fick mixed-CO and Fick corrected atrial-CO $(\mathrm{r}=0.93)$, there were significant differences between the measurements made at the four time points. When we corrected this value, differences no longer occurred and the correlation coefficient remained high $(r=0.94)$. The mean of the differences in $\mathrm{CO}$ in the four series of measurements was $-0.64 \pm 0.24$ L.min ${ }^{-1}(9.1 \pm 3.3 \%)$ for mixed blood and $0.14 \pm 0.18$ L.min ${ }^{1}(3.3 \pm 1.3 \%)$ for corrected atrial blood. This was similar to the difference described between the successive thermodilution measurements, which was $9.4 \pm 6.2 \%,{ }^{23}$ also remembering that $\mathrm{CO}$ presents a spontaneous variability of $10 \% .{ }^{24}$ In the present study we observed that the agreement between the two methods was satisfactory on the basis of the decisions made for treatment. We found mo difference between the methods that might culminate in incorrect therapy. According to Shoemaker et al. ${ }^{25}$ in any monitoring technique anxiety and hyperventilation can intensify the physiological responses. However, in an emergency situation, it is not so important to have the same accuracy as required for stable conditions, also because basal measurements are frequently unknown and optimal values for each patient can vary according to the co-morbidities present. On the other hand, in practice, a 10 to $15 \%$ difference between invasive and noninvasive $\mathrm{CO}$ estimate can be acceptable when changes of 30 to $50 \%$ of normal values are present. Thermodilution shows limited accuracy in situations of both high and low $\mathrm{CO}$, especially when the patient presents hypothermia, cardiac arrhythmia, shivering and anxiety, or when errors are made in terms of the temperature and volume of injection.

Early intervention in the treatment of septic shock is essential and is correlated with a decrease in mortality. In a recent study, Rivers et al. ${ }^{26}$ proposed an early strategy for the initial management of patients with septic shock. These investigators demonstrated a reduction in mortality rate from $46.5 \%$ to $30.5 \%$ when they compared the standard treatment strategy (guided by urinary output, MAP and CVP) to the early one. The early strategy included the measurement of central venous oxygen measurement $\left(\mathrm{SCO}_{2} \geq 70 \%\right)$, which served as a guide for the restoration of tissue perfusion. This early approach represents a crucial opportunity for rapid therapeutic interventions at the appropriate time to restore tissue perfusion, before the installation of irreversible organic dysfunction. Today, indirect calorimetry is definitely part of this arsenal for the early assessment of critically ill patients.

\section{Conclusion}

The present results permit us to conclude that indirect calorimetry is a good method for a less invasive measiurement of $\mathrm{CO}$ in patients victims of septic shock, presenting results similar to those obtained by thermodilution. The use of atrial venous blood for the 
calculatiopn of venous $\mathrm{O}_{2}$ content is well correlated with methods previously defined in the literature for $\mathrm{CO}$ calculation. The attempt to introduce a correction factor for atrial oxygen content was interesting, since there is a good approximation between $\mathrm{CO}$ values obtained with atrial blood and those obtained with mixed blood and thermodilution. However, further studies are needed to validate the use of this method in patients with septic shock admitted to intensive care units.

\section{References}

1. Shoemaker WC, Czer LS. Evaluation of the biological importance of various hemodynamics and oxygen transport variables: which variables should be monitored in postoperative shock? Crit Care Med. 1979;7:424-31.

2. Parker MM, Parrillo JE. Septic Shock: hemodynamics and pathogenesis. JAMA. 1983;250:3324-7.

3. Visscher MB, Johnson JA. The Fick principle: analysis of potential errors in its conventional application. J Appl Physiol. 1953;(5):635-45.

4. Davidson CJ, Bonow RO. Cardiac catheterization in: Braunwald E, Zipes DP, Libby, P (Eds). Heart Disease: Textbook of Cardiovascular Medicine. Philadelphia: W. B. Saunders Company. 2001:35986.

5. Bone RC, Balk RA, Cerra FB. Definitions for sepsis and organ failure and guidelines for the use of innovative therapies in sepsis. The ACCP/SCCM Consensus Conference Committee. American College of Chest Physicians/Society of Critical Care Medicine. Chest. 1992;(101):1644-55.

6. Knaus WA, Draper EA, Wagner DP, Zimmerman JE. Apache II: a severity of disease classification system. Crit Care Med. 1985;(13):818-29.

7. Elebute EA, Stoner HB. The grading of sepsis. $\mathrm{Br}$ J Surg. 1983;(70):29-31.

8. Hollander M, Wolfe DA. Nonparametric Statistical Methods. New York: John Wiley \& Sons, 1973.

9. Baylor P. Lack of agreement between thermodilution and fick methods in the measurement of cardiac output. J Intensive Care Med. 2006;21(2):93-8.

10. Konishi T, Nakamura Y, Morii I, Himura Y, Kumada T, Kawai C. Comparison of thermodilution and Fick methods for measurement of cardiac output in tricuspid regurgitation. Am J Cardiol. 1992;(70):5389.

11. Van Grondelle A, Ditchey RV, Groves BM, Wagner WW Jr, Reeves JT. Thermodilution method overestimates low cardiac output in humans. Am J Physiol. 1983;(245):H690-2.

12. Mahutte CK, Jaffe MB, Sassoon CS, Wong DH. Cardiac output from carbon dioxide production and arterial and venous oximetry. Crit Care Med. 1991;(19):1270-7.

13. Mahutte CK, Jaffe MB, Chen PA, Sasse SA, Wong DH, Sassoon CS. Oxygen Fick and modified carbon dioxide Fick cardiac outputs. Crit Care Med. 1994(22):86-95.

14. Mahutte CK, Jaffe MB. Effect of measurement errors on cardiac output calculated with $\mathrm{O} 2$ and modified CO2 Fick methods. J Clin Monit. 1995;(11):99-108.

15. Binder JC, Parkin WG. Non-invasive cardiac output determination: comparison of a new partialrebreathing technique with thermodilution. Anaesth Intensive Care 2001;(29):19-23.

16. Edwards JD, Mayall RM. Importance of the sampling site for measurement of mixed venous oxygen saturation in shock. Crit Care Med. 1998;(26):1356-60.

17. Cargill WH, Hickam JB. The oxygen consumption of the normal and diseased human kidney. J Clin Invest. 1949;(28):526-30.

18. Barratt-Boyes BG, Wood EH. The oxygen saturation of blood in the vena cava, right heart chambers and pulmonary vessels of healthy subjects. J Lab Clin Med 1957;(50):93-106.

19. Schienman MM, Brown MA, Rapaport E. Critical assessment of use of central venous oxygen saturation as a mirror of mixed venous oxygen in severely ill cardiac patients. Circulation. 1969;(40):165-72.

20. Tahvanainen J, Meretoja O, Nikki P. Can central venous blood replace mixed venous blood samples? Crit Care Med. 1982;(10):758-61.

21. Reinhart K, Rudolph T, Bredle DL, Hannemann L, Cain SM. Comparison of central-venous to mixedvenous oxygen saturation during changes in oxygen supply/demand. Chest 1989;(95):1216-21.

22. Lee J, Wright F, Baber R, Stanley L. Central venous oxygen saturation in shock: a study in man. Anesthesiology. 1972;(36):472-8.

23. Shoemaker WC, Parsa MH. Invasive and noninvasive monitoring. In: Shoemaker WC, Holbrook PR, Ayres SM (Eds). Textbook of Critical Care. Philadelphia: W. B. Saunders Company, 2000:74-91.

24. Sasse SA, Chen PA, Berry RB, Sassoon CS, Mahutte CK. Variability of cardiac output over time 
in medical intensive care unit patients. Crit Care Med. 1994;(22):225-32.

25. Shoemaker WC, Belzberg H, Wo CC, Milzman DP. Multicenter study of noinvasive monitoring systems as alternatives to invasive monitoring of acutely ill emergency patients. Chest. 1998;(114):1643-52.

26. Rivers E, Nguyen B, Havstad S. Early goal-directed therapy in the treatment of severe sepsis and septic shock. N Engl J Med. 2001;(345):1368-77.

\section{Acknowledgements}

FAPESP - Fundação de Amparo À Pesquisa do Estado de São Paulo and FAEPA - Fundação de Apoio ao Ensino, Pesquisa e Assistência do HCFMRP-USP.

\section{Correspondence:}

Intensive Care Unit - Ribeirão Preto Hospital of Clinics

Av. Bandeirantes, 3900 - Ribeirão Preto - SP

14049-900 Ribeirão Preto-SP, Brazil

Conflict of interest: none

Phone/Fax: (+55) 16 3602-2439

abasile@fmrp.usp.br

\section{How to cite this article:}

Martins MA, Coletto FA, Campos AD, Basile-Filho A. Indirect calorymetry can be used to measure cardiac output in septic patients? Acta Cir Bras. [serial on the Internet] 2008;23: Suppl 1. Available from URL: http://www.scielo.br/acb.

\section{Comments:}

This report provides evidences that thermodilution and indirect calorimetry can be equally used to evaluate cardiac output during septic shock. The study was performed in nineteen patients with septic shock and indication of invasive hemodynamic monitoring. Four cardiac output measurements were done during eight hours, on average, by the two methods. The positive finding of this study is to demonstrate that a less invasive method, indirect calorimetry, can be used in severe sepsis adding important data in order to help clinical decisions

\section{Carlos Gilberto Carlotti Junior}

$\mathrm{PhD}$, Associate Professor, Division of Neurosurgery, Department of Surgery and Anatomy, Ribeirão Preto Faculty of Medicine, University of São Paulo, Brazil.

\section{Ajith Kumar Sankarankutty}

PhD, Professor of Division of Digestive Surgery, Department of Surgery and Anatomy, Ribeirão Preto Faculty of Medicine, University of São Paulo, Brazil.

\section{Comments:}

The study shows monitoring of cardiac debit, as a essential factor in clinical conditions involving haemodynamic instability and as one of the most important variables in the tissue perfusion context. Martins et al. compare cardiac debit measurements by thermodilution and indirect calorimetry in septic shock patients, and clearly justify the last method as a good one for this purpose. It is a non- invasive method furnishing important patient management data, especially total body oxygen consumption, $\mathrm{CO}_{2}$ production and the respiratory coefficient. It is emphasized that calorimetry is an important tool, especially in cases where invasive hemodynamic monitoring is not available or contraindicated.

\section{Luis Fernando Tirapelli}

MD, PhD, Department of Surgery and Anatomy, Ribeirão Preto Faculty of Medicine, University of São Paulo, Brazil.

\section{Comments:}

Critically ill patients require a strict evaluation of their hemodynamic state through circulatory data. Calorimetric evaluation could be considered as the method least invasive and this imparts importance to this study. However, it should be stressed that calorimetry application is limited to patients under mechanical ventilation with a fraction of oxygen under 0.6 , thus excluding a great number of patients considered seriously ill and who could be only evaluated by the Swan-Ganz catheter. On the other hand, a curious reader could ask why the authors failed to document the difficulty in the clinical application of calorimetry, as well as the possible complications to these patients induced by invasive procedures. The study was conducted in a coherent manner and the results supporting the proposed objective were appropriately analyzed statistically. It searches relevant options and is important in clinical application.

\section{Walter Campos}

MD, PhD, Department of Surgery and Anatomy, Ribeirão Preto Faculty of Medicine, University of São Paulo, Brazil. 